\title{
Perbandingan Model Bisnis Perusahaan Jaringan Transportasi di Indonesia Dalam Perspektif Platform Design Toolkit v.2
}

\author{
Hafizudin Wirawan, Arif Wibisono, dan Amna Shifia Nisafani. \\ Departemen Sistem Informasi, Fakultas Teknologi Informasi, Institut Teknologi Sepuluh Nopember \\ (ITS) \\ e-mail: arif.wibisono@gmail.com
}

\begin{abstract}
Abstrak-Pasar layanan jaringan transportasi cukup luas dan terus mengalami pertumbuhan setiap tahun. Akan tetapi pemain kunci di dalam bisnis ini masih didominasi oleh pemain lama seperti Go-Jek, Grab, dan Uber. Penelitian ini bertujuan untuk membandingkan model-model bisnis yang diterapkan oleh platform perusahaan jaringan transportasi. Dalam melakukan perbandingan, penelitian ini menggunakan framework Platform Design Toolkit v.2 (PDT). Di dalam PDT terdapat sembilan komponen model bisnis yang akan dianalisis: Platform owner, Platform stakeholders, Peers, Partners, Transactions, Channel and Context, Services, Value propositions, Infrastructure and Core Components. Data didapatkan melalui web review, app review, dan literature review. Penelitian ini mengambil studi kasus perusahaan jaringan transportasi di Indonesia. Penelitian memilih Indonesia, karena Indonesia adalah negara dengan nilai ekonomi terbesar di ASEAN. Ada 4 perusahaan yang kami analisis antara lain: Go-Jek, Grab, Uber, Ojek Syar'i. Hasil dari studi ini adalah pemetaan perbandingan model bisnis antara perusahaan jaringan transportasi di Indonesia. Dalam penelitian ini ditemukan faktafakta mengenai model bisnis perusahaan jaringan transportai di Indonesia. Fakta tersebut antara lain mengenai peran penting investor asing terhadap perkembangan perusahaan jaringan transportasi, nilai unggul armada sebuah perusahaan jaringan transportasi, mitra-mitra dari perusahaan jaringan transportasi, channel yang diberikan perusahaan untuk berkomunikasi dengan pengguna, dan nilai unggul layanan dari perusahaan jaringan transportasi satu diantara lainnya. Hasil dari perbandingan ini dapat digunakan calon consumers dan calon producers dapat memilih platform jaringan transportasi yang mana yang cocok untuk mereka berdasarkan pemetaan tersebut
\end{abstract}

Kata Kunci-Transportation Network Company, Ride Sourcing, Platform Design Toolkit, Business Model.

\section{PENDAHULUAN}

$\mathrm{P}$ ERKEMBANGAN perkonomian dunia masih dibilang dalam keadaan yang cukup tinggi. Bank Dunia mengatakan bahwa di tahun 2016 mengalami penurunan dari 3,4 persen menjadi 3,1 persen [1,2]. Namun angka tersebut masih dinilai tinggi. United Nation Departement of Economic memprediksikan perkembangan perekonomian dunia akan meningkat lebih dari 3,2 persen di tahun 2017 [1]-[2]. Meningkatnya pertumbuhan berikutnya ekonomi dunia mengakibatkan tumbuhnya pula pasar internasional [3].

Dengan tumbuhnya pasar internasional, menyebabkan pula perkembangan ICT di setiap negara. Perkembangan ICT dunia terus meningkat setiap tahunnya [4]. Perkembangan ICT terlihat dengan menyebarnya fasilitas internet di setiap negara. Hal tersebut mengakibatkan terus meningkatnya pengguna smartphone. Di tahun 2013 45\% masyarakat sudah memiliki smartphone, dan meningkat hingga 54\% di tahun 2015 [5]. Hingga saat ini hampir setiap orang sudah memiliki smartphone masing-masing [6]

Dari Fakta tersebut mengakibatkan munculnya platformplatform yang berbasis smartphone. Salah satunya adalah platform ridesourcing. TNC (perusahaan dari platform ridesourcing) berawal pada tahun 2012 oleh California Public Utilities Commission. Pada saat itu dibuatkan reguluasi mengenai beroperasinya TNC [7]. Hingga saat ini banyak TNC yang sudah berkembang diantaranya Lyft, Uber, Grab, Getaround, Sidecar,dan lain-lain [8]. Di Indonesia sendiri sudah beroperasi beberapa TNC diantaranya Grab, Uber, dan TNC local yaitu Go-Jek. Terdapat juga beberapa TNC yang beroperasi regional (hanya beberapa kota) yaitu Ojek Syar'i,. Namun seperti yang diketahui, terdapat banyak sekali TNC yang sudah beroperasi. Setiap TNC memiliki keunggulan masing-masing. Sampai sekarang belum pernah ada penelitian yang membahas tentang model bisnis apa yang membuat sebuah platform TNC lebih unggul daripada yang lain.

Riset ini membahas tentang bagaimana sebuah platform TNC dapat lebih unggul daripada platform TNC lainnya. Belum pernah ada riset khusus yang membahas tentang bagaimana sebuah platform TNC lebih unggul daripada platform TNC lainnya. Mayoritas riset terkait platform TNC berfokus pada tahapan perbandingan antara jasa transportasi biasa dengan layanan jasa transportasi berbasis online Fransisco S. Fransisco $\mathrm{S}$ membuat penelitian mengenai dampak fenomena ridesourcing dengan transportasi public biasanya.(source). Dia menemukan bahwa ridesourcing cukup diminati oleh warga San Fransisco. Frasnsisco S. juga menjelaskan mengenai karakteristik warga San Fransisco terhadap layanan transportasi public dan layanan dari TNC. Namun, penelitian membandingkan antara transportasi public konvensional dengan yang berbasis online saja.

Penelitian ini berfokus pada menilai dan membandingkan platform TNC. Dalam penilitan ini akan menjelaskan tentang bagaimana sebuah platform TNC dapat unggul daripada lainnya. Penelitian ini sangat penting untuk pemilik bisnis TNC supaya mengetahui nilai tambah apa yang perlu diberikan pada platform TNC nya supaya dapat unggul dalam persaingan. Penelitian ini juga penting calon penumpang ingin 
menggunakan layanan TNC supaya sesuai dengan kebutuhannya. Dalam penelitian ini akan menggunakan pemodelan bisnis Platform Design Toolkit v2. Dengan Framework Platform Design Toolkit v.2 ini memudahkan penelitian untuk melihat banyak perspektif dalam sebuah bisnis. Terdapat sembilan komponen yang terdapat dalam framework Platform Design Toolkit v.2 yaitu Platform owner, Platform stakeholders, Peers, Partners, Transactions, Channel and context, Services, Value propositions, Infrastructure and Core Components[9]. Framework ini mendukung penelitian ini karena dapat melihat apa yang menyebabkan sebuah platform TNC lebih unggul daripada lainnya dengan melihat dari perspektif yang terdapat dalam framework tersebut. Dengan framework Platform Design Toolkit v.2 dapat melihat apakah sebuah platform TNC unggul karena orientasi nya terhadap partner, atau Value dari sebuah TNC tersebut yang lebih daripada lainnya dan sebagainya

\section{DASAR TEORI}

\section{A. Transportation Network Company}

Transportation Network Company (TNC) merupakan perusahaan yang dapat menghubungkan antara penumpang dengan supir. TNC melakukan hal tersebut melalui sebuah platform baik berupa apps maupun website [10]. Sopir dari TNC harus mengunduh platform untuk mendapatkan penumpang yang ingin menggunakan jasa transportasi. Sopir akan mendapat fee setelah berhasil mengantar penumpang ke tujuan. Regulasi pertama mengenai TNC dibuat pada 20 Desember 2012 oleh California Public Utilities Commission. Pembuatan regulasi itu dihadiri oleh Uber, SideCar, dan Lyft [11]. Hingga saat ini TNC sudah berkembang di masyarakat. Di Indonesia sendiri terdapat perusahaan Uber, Grab, dan GoJek yang sudah beroperasi.

\section{B. Platform Design Toolkit v.2}

Platform Design Toolkit merupakan konsep yang dibuat oleh Simon Ciero dan timnya. Platform Design Toolkit merupakan sebuah modifikasi dari framwork business model canvas yang dibuat oleh Alexander Ostwalder. Tujuan dari Platform Design Toolkit adalah sebagai bahasa yang dapat mendeskripsikan dan memanipulasi sebuah model platform supaya dapat memikirkan strategi alternatif untuk platform tersebut. Penelitian ini menggunakan Platform Design Toolkit karena framework tersebut dapat melihat sebuah strategi platform secara general. sehingga dapat membandingkan block apa yang membuat open source software ERP unggul daripada lainnya. Terdapat 9 block di dalam Platform Design Toolkit v.2 yaitu Platform owner, Platform stakeholders, Peers, Partners, Transactions, Channel and Context, Services, Value propositions, Infrastructure and Core Components.

\section{Google Play Store}

Google Play Store merupakan app store yang dimiliki oleh Google. Pada awalnya aplikasi ini bernama Android Market [12]. Google Play Store merupakan salah satu dari mobile app store populer di dunia. Google Play Store adalah sebuah digital distribution yang dapat memungkinkan user untuk mencari dan download aplikasi. Dalam Google Play Store developer juga dapat upload aplikasi yang dibuat dan melakukan pembaharuan supaya terus dinikmati pengguna. Google Play Store menjadi salah satu key performance indicator penelitian ini karena terdapat pengurutan peringkat aplikasi. Pengurutan peringkat aplikasi berdasarkan kategori aplikasi, Daily Installs, SEO, rating aplikasi, seberapa sering aplikasi digunakan, dan banyaknya search kepada aplikasi tersebut (how to top rank)

\section{Apple App Store (iOS)}

Pada Juli 2008, Apple merilis Online App Store untuk para pengguna iPhone. Apple App Store pengguna iPhone dapat mencara berbagai macam aplikasi dari third party developers. Dalam Apple App Store terdapat berbagai macam aplikasi baik aplikasi berbayar maupun gratis. Di tahun 2009 Apple App Store (iOS) mencapai 1 milyar download dan pada tahun 2013 Apple App Store (iOS) sudah mencapai 10 milyar download. Apple App Store menjadi salah satu key performance indicator karena di dalam Apple App Store (iOS) juga terdapat pengurutan peringkat aplikasi yang dapat dijadikan penilaian sebuah platform / applikasi.

\section{METODOLOGI}

Pengerjaan studi ini tersusun atas beberapa langkah yang sistematis. Langkah-langkah pengerjaan studi dari awal hingga akhir ditunjukkan pada.

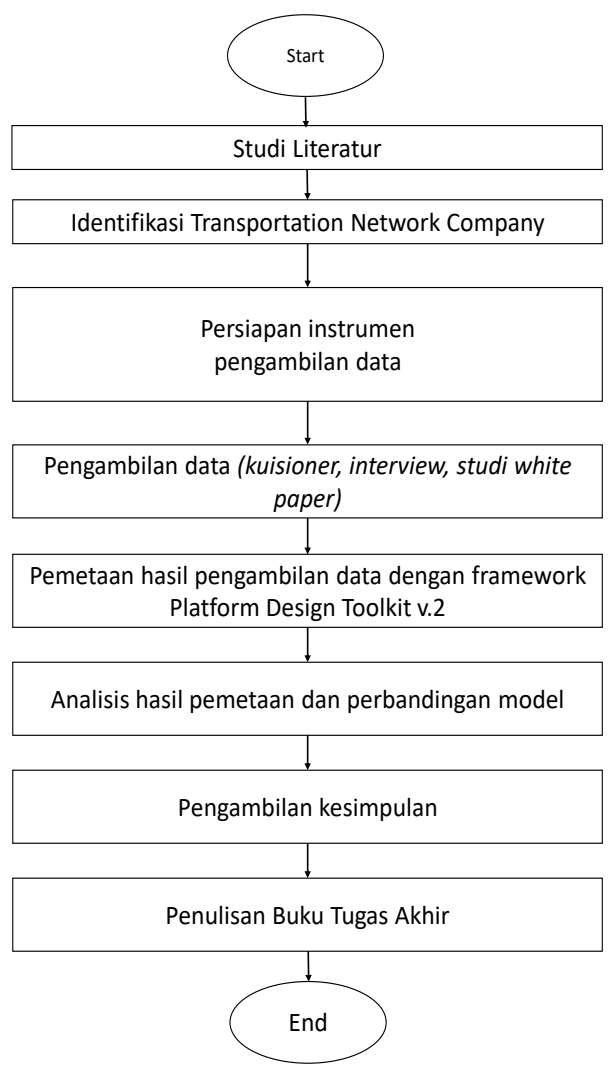

Gambar 1. Metodologi Penelitian 


\section{HASIL DAN ANALISIS}

\section{A. Analisa Platform Owners}

Dalam Platform Owners terdapat pengelompokan yaitu Owner / manajemen pusat dari luar negeri dan dari dalam negeri. Berikut merupakan pemetaan Platform Owners melalui hasil pemetaan bab perancangan.

Tabel 1.

Pemetaan Bab Perancangan

\begin{tabular}{lllll}
\hline \hline $\begin{array}{l}\text { Transportation } \\
\text { Compark }\end{array}$ & $\begin{array}{l}\text { Manajemen } \\
\text { pusat dalam } \\
\text { negeri }\end{array}$ & $\begin{array}{l}\text { Manajemen } \\
\text { Pusat Luar } \\
\text { negeri }\end{array}$ & $\begin{array}{l}\text { Usia } \\
\text { Platform } \\
\text { di } \\
\text { Indonesia }\end{array}$ & $\begin{array}{l}\text { Usia } \\
\text { Platform }\end{array}$ \\
\hline Go-Jek & $\checkmark$ & - & 6 tahun & 6 tahun \\
Grab & - & $\checkmark$ & 3 tahun & 5 tahun \\
Uber & - & $\checkmark$ & 3 tahun & 8 tahun \\
Ojessi & $\checkmark$ & - & 2 tahun & 2 tahun \\
\hline \hline
\end{tabular}

Dari hasil pemetaan diatas didapatkan bahwa :

- Go-Jek merupakan platform Transportation Network Company tertua di Indonesia

- Kecenderungan TNC di Indonesia berbadan hukum PT

\section{B. Analisa Platform Stakeholders}

Dalam Platform Stakeholders terdapat kecenderungan yaitu para investor yang mendukung jalannya platform tersebut. Berikut merupakan pemetaan Platform Stakeholders dari masing-masing platform :

Tabel 2.

Pemetaan Platform Stakeholders

\begin{tabular}{lllll}
\hline \hline $\begin{array}{l}\text { Platform } \\
\text { Stakeholders }\end{array}$ & Go-Jek & Grab & Uber & Ojessi \\
\hline $\begin{array}{l}\text { Investor Luar } \\
\text { Negeri }\end{array}$ & $\checkmark$ & $\checkmark$ & $\checkmark$ & - \\
$\begin{array}{l}\text { Investor Dalam } \\
\text { Negeri }\end{array}$ & - & $\checkmark$ & - & $\checkmark$ \\
$\begin{array}{l}\text { Jumlah } \\
\text { investor }\end{array}$ & 11 & 12 & 79 & - \\
$\begin{array}{l}\text { Total Investasi } \\
\text { Pemerintah }\end{array}$ & $\$ 1.75 \mathrm{~B}$ & $\$ 1.44 \mathrm{~B}$ & $\$ 8.81 \mathrm{~B}$ & - \\
\hline \hline
\end{tabular}

Dari hasil pemetaan diatas didapatkan bahwa :

- Perkembangan Transportation Network Company sangat berbanding lurus dengan jumlah investasi pada platform tersebut

- Perkembangan Transportation Network Company di Indonesia tidak bisa lepas dari peran investor asing

- Tidak banyak investor local yang membantu jalannya TNC di Indonesia

- Pemerintah memiliki peran penting dalam jalannya Transportation Network Company

\section{Analisa Peers Consumers}

Peers Consumer merupakan entitas yang mengkonsumsi value dari platform. Dalam pemetaan yang dilakukan bab 4 terdapat kecenderungan dalam mengelompokkan peers consumers. Berikut merupakan pemetaan peers consumers :
Tabel 3.

Pemetaan Peers Consumers

\begin{tabular}{llcll}
\hline \hline $\begin{array}{l}\text { Transportation } \\
\text { Network Company }\end{array}$ & Go-Jek & Grab & Uber & Ojessi \\
\hline $\begin{array}{l}\text { Penumpang } \\
\text { Personal }\end{array}$ & $\checkmark$ & $\checkmark$ & $\checkmark$ & $\checkmark$ \\
$\begin{array}{l}\text { Penumpang Bisnis } \\
\text { Penumpang }\end{array}$ & - & $\checkmark$ & $\checkmark$ & - \\
keluarga & - & - & $\checkmark$ & - \\
$\begin{array}{l}\text { Penumpang } \\
\text { berlangganan } \\
\text { (Scheduled) }\end{array}$ & - & $\checkmark$ & $\checkmark$ & $\checkmark$ \\
\hline
\end{tabular}

Dari hasil pemetaan diatas didapatkan bahwa :

- Semakin banyak pengkategorian peers consumers yang dilakukan oleh Transportation Network Company semakin baik sebuah sebuah Transportation Network Company dalam melakukan diferensiasi dan positioning terhadap pelanggan

- Uber memiliki strategi terbaik dalam pengkategorian peers consumers

- Kecenderungan strategi Transportation Network Company pada pengkategorian peers consumers adalah penumpang insidentil, penumpang bisnis, penumpang terjadwal

\section{Analisa Peers Producers}

Peers producers merupakan entitas yang membuat value dari platform dalam hal ini adalah pengendara dari TNC tersebut. Berikut merupakan hasil pemetaan dari peers producers dari masing-masing TNC :

Tabel 4.

Pemetaan Dari Peers Producers Dari Masing-Masing TNC

\begin{tabular}{lllll}
\hline \hline Peers Producer & Go-Jek & Grab & Uber & Ojessi \\
\hline $\begin{array}{l}\text { Pengendara } \\
\text { Motor }\end{array}$ & $\checkmark$ & $\checkmark$ & $\checkmark$ & $\checkmark$ \\
$\begin{array}{l}\text { Pengendara } \\
\begin{array}{l}\text { Mobil } \\
\text { Pengendara }\end{array}\end{array}$ & $\checkmark$ & $\checkmark$ & $\checkmark$ & - \\
Taxi & & $\checkmark$ & - & - \\
\hline
\end{tabular}

Dari hasil pemetaan diatas didapatkan bahwa :

- Semakin banyak sebuah Transportation Network Company semakin mempercepat pengguna mendapatkan pengemudi dan menuju tempat tujuan (mempercepat respond time)

- Go-Jek dan Grab memiliki strategi terbaik dalam pengkategorian peers consumers

- Kecenderungan strategi Transportation Network Company pada pengkategorian peers Producers adalah pengendara mobil, pengendara motor, dan pengendara taxi

\section{E. Analisa Partners}

Partners merupakan entitas professional yang berkolaborasi kepada platform untuk memberikan value lebih. Berikut merupakan kecenderungan partners yang dimiliki oleh TNC:

Tabel 5.

Kecenderungan Partners Yang Dimiliki Oleh TNC

\begin{tabular}{lllll}
\hline \hline Partners & Go-Jek & Grab & Uber & Ojessi \\
\hline Perbankan & $\checkmark$ & $\checkmark$ & $\checkmark$ & - \\
$\begin{array}{l}\text { Showroom } \\
\text { mobil }\end{array}$ & - & $\checkmark$ & $\checkmark$ & - \\
$\begin{array}{l}\text { Showroom } \\
\text { motor }\end{array}$ & $\checkmark$ & - & - & - \\
\hline \hline
\end{tabular}




\begin{tabular}{lcccc}
\hline \hline Retail & $\checkmark$ & - & - & - \\
smartphone & & & - \\
$\begin{array}{l}\text { Minimarket/ } \\
\text { Retail }\end{array}$ & $\checkmark$ & $\checkmark$ & - & - \\
$\begin{array}{l}\text { Tenant } \\
\text { makanan }\end{array}$ & $\checkmark$ & - & $\checkmark$ & - \\
Asuransi & $\checkmark$ & $\checkmark$ & - & - \\
Marketplace & $\checkmark$ & $\checkmark$ & - & - \\
Event Lokal & $\checkmark$ & - & $\checkmark$ & - \\
Koperasi & $\checkmark$ & $\checkmark$ & - & - \\
SMB & $\checkmark$ & - & - & \\
$\begin{array}{l}\text { Hotel and } \\
\text { travel }\end{array}$ & $\checkmark$ & - & & \\
\hline
\end{tabular}

Dari hasil pemetaan diatas didapatkan bahwa :

- Dalam strategi partners tergolong menjadi 2 oritentasi. Partners yang berorientasi memperkuat consumers, dan partners yang berorientasi memperkuat producers

- Kecenderungan strategi partners Transportation Network Company untuk memperkuat producers adalah bermitra dengan showroom kendaraan, kopersasi, dan asuransi

- Kecenderungan strategi partners Transportation Network Company untuk memperkuat consumers adalah bermitra dengan perbankan dan partners yang dapat menambahkan reward dan promo platform

\section{F. Analisa Transactions}

Transactions adalah aksi yang dilakukan peers untuk mendapatkan value dari platform. Berikut merupakan hasil pemetaan block transactions dari masing-masing Transportation Network Company : Tabel 6.

Pemetaan Block Transactions Dari Masing-Masing Transportation

\begin{tabular}{|c|c|c|c|c|}
\hline \multicolumn{5}{|c|}{ Network Company } \\
\hline Transactions & "Go-Jek & Grab & Uber & Ojessi \\
\hline $\begin{array}{l}\text { Melakukan } \\
\text { pemesenanan ke } \\
\text { pengemudi }\end{array}$ & $\checkmark$ & $\checkmark$ & $\checkmark$ & $\checkmark$ \\
\hline $\begin{array}{l}\text { Membayar } \\
\text { perjalanan }\end{array}$ & $\checkmark$ & $\checkmark$ & $\checkmark$ & $\checkmark$ \\
\hline $\begin{array}{l}\text { Memberikan } \\
\text { feedback pada } \\
\text { pengemudi }\end{array}$ & $\checkmark$ & $\checkmark$ & $\checkmark$ & $\checkmark$ \\
\hline $\begin{array}{l}\text { Melakukan SMS } \\
\text { ke pengemudi }\end{array}$ & $\checkmark$ & $\checkmark$ & $\checkmark$ & $\checkmark$ \\
\hline $\begin{array}{l}\text { Melakukan } \\
\text { pembayaran } \\
\text { melalui e-money } \\
\text { platform }\end{array}$ & $\checkmark$ & $\checkmark$ & - & - \\
\hline $\begin{array}{l}\text { Melakukan in- } \\
\text { app chat }\end{array}$ & - & $\checkmark$ & - & - \\
\hline $\begin{array}{l}\text { Melakukan } \\
\text { panggilan } \\
\text { telepon }\end{array}$ & $\checkmark$ & $\checkmark$ & $\checkmark$ & $\checkmark$ \\
\hline $\begin{array}{l}\text { Melakukan top- } \\
\text { up E-money } \\
\text { platform }\end{array}$ & $\checkmark$ & $\checkmark$ & - & - \\
\hline
\end{tabular}

Dari hasil pemetaan diatas didapatkan bahwa :

- Kecenderungan strategi transactions transportation network company adalah melakukan pemesanan ke pengemudi, melakukan pembayaran, pemberian feedback untuk pengemudi, melakukan SMS ke pengemudi, melakukan panggilan telepon
- Grab memiliki strategi unik yang tidak dimiliki platform transportation network company lain adalah yaitu dapat fitur in app-chat

\section{G. Analisa Channels and Context}

Channels and context adalah bagaimana platform menyediakan tempat untuk peers melakukan transaction. Berikut merupakan hasil pemetaan dari channels and context dari masing-masing transportation network company :

Tabel 7.

Hasil Pemetaan Dari Channels And Context Dari Masing-Masing Transportation Network Company

\begin{tabular}{lllll}
\hline \hline $\begin{array}{l}\text { Channels } \\
\text { and Context }\end{array}$ & Go-Jek & Grab & Uber & Ojessi \\
\hline Apps & $\checkmark$ & $\checkmark$ & $\checkmark$ & \\
Live & $\checkmark$ & $\checkmark$ & $\checkmark$ & $\checkmark$ \\
\hline \hline
\end{tabular}

Dari hasil pemetaan diatas didapatkan bahwa :

- Aplikasi merupakan channels yang dibentuk antara producers dan consumers

- Kegiatan yang dilakukan dalam aplikasi adalah melakukan pemesanan, memberikan feedback kepada pengemudi, melakukan SMS, melakukan pembayaran dengan E-Money, dan melukan panggilan telepon

- Live merupakan context yang dibentuk antara producers dan consumers

- Kegiatan yang dilakukan dalam live (pertemuan) adalah saat perjalanan dan melakukan pembayaran secara cash

\section{H. Analisa Enabling Services}

Enabling Services merupakan cara yang diberikan platform kepada partner supaya dapat memulai menghasilkan value. Berikut merupakan pemetaan dari enabling services masingmasing platform :

Tabel 8.

Pemetaan Dari Enabling Services Masing-Masing Platform

\begin{tabular}{|c|c|c|c|c|}
\hline $\begin{array}{l}\text { Enabling } \\
\text { Services }\end{array}$ & Go-Jek & Grab & Uber & Ojessi \\
\hline $\begin{array}{l}\text { Rekomendasi } \\
\text { dalam aplikasi }\end{array}$ & $\checkmark$ & $\checkmark$ & $\checkmark$ & - \\
\hline $\begin{array}{l}\text { Rekomendasi } \\
\text { dalam website }\end{array}$ & $\checkmark$ & $\checkmark$ & $\checkmark$ & - \\
\hline \multicolumn{5}{|c|}{$\begin{array}{l}\text { Dari hasil pemetaan diatas didapatkan bahwa: } \\
\text { - Rekomendasi pada web merupakan salah satu strategi } \\
\text { enabling services untuk membantu partners yang butuh } \\
\text { direkomendasikan secara procedural / perlu penjelasan } \\
\text { panjang }\end{array}$} \\
\hline
\end{tabular}

- Rekomendasi pada aplikasi merupakan salah satu strategi enabling services untuk membantu partners yang butuh direkomendasikan secara practical

\section{Analisa Emprowing Services}

Emprowing services merupakan cara yang diberikan platform kepada peers producers. Service ini bertujuan untuk mempermudah peers producer untuk terus menciptakan value. Berikut merupakan pemetaan emprowing services dari masingmasing TNC:

Tabel 9.

Pemetaan Emprowing Services Dari Masing-Masing TNC

\begin{tabular}{lllll}
\hline \hline Emprowing & Go-Jek & Grab & Uber & Ojessi \\
Services & & & & \\
\hline Asuransi & $\checkmark$ & $\checkmark$ & $\checkmark$ & - \\
Heatspot & - & $\checkmark$ & $\checkmark$ & - \\
GPS & $\checkmark$ & - & $\checkmark$ & - \\
\hline \hline
\end{tabular}




\begin{tabular}{lcccc}
\hline \hline Pro-Tips & - & - & $\checkmark$ & - \\
Sewa/cicil & - & $\checkmark$ & $\checkmark$ & - \\
kendaraan & & & & \\
mobil & & & - & \\
$\begin{array}{l}\text { Sewa/cicil } \\
\text { kendaraan }\end{array}$ & $\checkmark$ & & & \\
motor & & & & \\
Tabungan & $\checkmark$ & - & & \\
Haji/umrah & & & $\checkmark$ & $\checkmark$ \\
Training & $\checkmark$ & $\checkmark$ & $\checkmark$ & $\checkmark$ \\
Driver reward & $\checkmark$ & $\checkmark$ &
\end{tabular}

Dari hasil pemetaan diatas didapatkan bahwa :

- Kecenderungan strategi Emprowing Services transportation network company adalah Asuransi, Training, dan driver reward, fitur heatspot, dan GPS

- Strategi sewa/cicil kendaraan dapat menjadi faktor penunjang perkembangan Transportation Network Company karena dapat menambah jumlah armada

- Go-Jek memiliki strategi yang tidak dimiliki yang lain yaitu fitur tabungan haji dan umrah untuk pengendara

- Uber memiliki strategi yang tidak dimiliki yang lain yaitu pro tips untuk pengemudi baru

\section{J. Analisa Other Services}

Other Services merupakan layanan pelengka bagi peers consumer. Di dalam other services terdapat kecenderungan dalam strategi TNC. Berikut merupakan pemetaan strategi Other Services:

Tabel 10.

pemetaan strategi Other Services

\begin{tabular}{lllll}
\hline \hline Other Services & Go-Jek & Uber & Grab & Ojessi \\
\hline Cashback & - & $\checkmark$ & - & - \\
Reward and & $\checkmark$ & - & $\checkmark$ & - \\
Promo & & & & \\
Hotline & $\checkmark$ & - & $\checkmark$ & $\checkmark$ \\
Discount & $\checkmark$ & - & $\checkmark$ & - \\
E-money & $\checkmark$ & - & $\checkmark$ & - \\
\hline \hline
\end{tabular}

Dari hasil pemetaan diatas didapatkan bahwa :

- Kecenderungan strategi Other services transportation network company adalah fitur hotline, pengadaan reward and promo, pengadaan discount, e-money dan hotline

- E-Money merupakan strategi yang dapat mempermudah pengguna untuk melakukan pembayaran

- Strategi E-Money mendukung program pemerintah dalam mengurangi uang kertas

- E-Money, reward and promo, dan discount dapat memperbesar customer base transportation network company

\section{K. Analisa Core Value Proposition}

Core Value Proposition merupakan layanan utama yang diberikan oleh platform kepada peers consumersnya. Core value proposition dapat terlihat dari tagline dan visi dari platform. Berikut merupakan pemetaan dari tagline dan visi masingmasing platform :

Tabel 11.

Pemetaan Dari Tagline Dan Visi Masing-Masing Platform

\begin{tabular}{|c|c|c|c|c|}
\hline No. & Platform & Tagline & Vision/mission & Lingkup \\
\hline 1 & Go-Jek & $\begin{array}{l}\text { "An Ojekfor } \\
\text { Every Need" }\end{array}$ & $\begin{array}{l}\text { "Unleashing } \\
\text { social impact } \\
\text { through } \\
\text { technology" }\end{array}$ & Indonesia \\
\hline
\end{tabular}

\begin{tabular}{|c|c|c|c|c|}
\hline 2 & Grab & $\begin{array}{l}\text { "South East } \\
\text { Asia Leading } \\
\text { Ride-Hailing } \\
\text { Platform" }\end{array}$ & $\begin{array}{l}\text { "Our vision is } \\
\text { to drive } \\
\text { Southeast Asia } \\
\text { transportation } \\
\text { forward and } \\
\text { transform the } \\
\text { region's } \\
\text { mobile internet } \\
\text { ecosystem" }\end{array}$ & $\begin{array}{l}\text { Asia } \\
\text { Tenggara }\end{array}$ \\
\hline 3 & Uber & "Get There" & $\begin{array}{l}\text { "Smarter } \\
\text { transportation } \\
\text { with fewer } \\
\text { cars and } \\
\text { greater } \\
\text { access" }\end{array}$ & Dunia \\
\hline 4 & Ojessi & $\begin{array}{l}\text { "Layanan ojek } \\
\text { wanita } \\
\text { pertama dan } \\
\text { terpercaya" }\end{array}$ & $\begin{array}{l}\text { "Melindungi } \\
\text { perempuan" }\end{array}$ & Indonesia \\
\hline
\end{tabular}

Dari hasil pemetaan diatas didapatkan bahwa :

- Setiap Transportation Network Company memiliki focus utama yang berbeda-beda

- Go-Jek melakukan pengembangan bisnis nya kearah layanan sehingga memunculkan lifestyle di kalangan consumers

- Grab melakukan pengembangan bisnis nya kearah perjalanan se-asia tenggara

- Uber melakukan pengembangan bisnis kearah perjalanan secara global

- Ojek Syari memiliki pengembangan bisnis kearah perjalanan khusus wanita

\section{Analisa Ancillary Value Proposition}

Ancillary proposition merupakan layanan penunjang yang diberikan pada peers. Bisa memiliki target yang sama dengan core value propositions. Berikut merupakan pemetaan ancillary value proposition dari masing-masing platform :

Tabel 12.

Pemetaan Ancillary Value Proposition Dari Masing-Masing Platform

\begin{tabular}{lllll}
\hline \hline $\begin{array}{l}\text { Ancillary Value } \\
\text { Proposition }\end{array}$ & Go-Jek & Uber & Grab & Ojessi \\
\hline $\begin{array}{l}\text { E-Money } \\
\text { Reward and }\end{array}$ & $\checkmark$ & - & $\checkmark$ & - \\
$\begin{array}{l}\text { promo } \\
\text { Pengkreditan }\end{array}$ & - & $\checkmark$ & $\checkmark$ & - \\
$\begin{array}{l}\text { kendaraan untuk } \\
\text { supir }\end{array}$ & & & $\checkmark$ & - \\
Driver Reward & $\checkmark$ & $\checkmark$ & $\checkmark$ & - \\
\hline
\end{tabular}

Dari hasil pemetaan diatas didapatkan bahwa :

- Kecenderungan strategi Ancillary Value Propositions transportation network company adalah E-Money, reward and promo, pengkreditan kendaraan, dan driver reward

\section{Analisa Infrastructure and Core Components}

Infrastructure and core components merupakan block yang berisi tentang bagian utama yang membuat seluruh proses bisnis dalam platform dapat berjalan dengan baik. Berikut merupakan pemetaan infrastructure and core components dari masingmasing Transportation Network Company : 
Tabel 13

Pemetaan Infrastructure And Core Components Dari Masing-Masing Transportation Network Company

\begin{tabular}{|c|c|c|c|c|}
\hline $\begin{array}{l}\text { Infrastructure } \\
\text { and Core } \\
\text { Components }\end{array}$ & Go-Jek & U Uber & Grab & Ojessi \\
\hline Web & $\checkmark$ & $\checkmark$ & $\checkmark$ & $\checkmark$ \\
\hline Mobile App & $\checkmark$ & $\checkmark$ & $\checkmark$ & $\checkmark$ \\
\hline
\end{tabular}

Dari hasil pemetaan diatas didapatkan bahwa :

- Komponen web dalam strategi infrastructure and core components adalah untuk menjelaskan layanan-layanan yang ada

- Komponen aplikasi dalam strategi infrastructure and core components adalah untuk menjalankan seluruh proses bisnis layanan

\section{KESIMPULAN}

Pada studi ini peneliti ingin mengetahui mengenai perbandingan strategi transportation network company di Indonesia dalam perspektif Platform Design Toolkit v.2. Penelitian dilakukan selama 4 bulan sejak bulan Januari 2017. Dalam penelitian ini dilakukan metode web review, platform review, dan literature review mengenai strategi yang diterapkan oleh transportation network company di Indonesia. Dari hasil analisis yang dilakukan dalam penelitian ini didapatkan kesimpulan sebagai berikut :

1. Entitas pemerintah, koperasi, dan investor asing merupakan entitas yang penting dalam block Platform Stakeholders.

2. Platform TNC besar yang beroperasi di Indonesia memiliki kecenderungan untuk mengkategorian pada peers consumers yaitu penumpang personal, penumpang bisnis, dan penumpang terjadwal (scheduled).

3. Platform TNC besar yang beroperasi di Indonesia memiliki kecenderungan untuk mengkategorian pada peers producers untuk TNC adalah pengemudi motor, pengemudi mobil, dan pengemudi taxi.

4. Kecenderungan strategi partners untuk platform TNC dalam memperkuat peers producers adalah bermitra dengan showroom, retail smartphone, dan asuransi. Sedangkan Kecenderungan strategi partners untuk consumers adalah perbankan, asuransi, marketplace, dan beberapa partner untuk memperkuat promo and reward seperti hotel dan travel

5. Kecendurungan strategi transactions yang digunakan oleh platform TNC besar yang beroperasi di Indonesia adalah melakukan pemesanan ke pengemudi, melakukan pembayaran, pemberian feedback untuk pengemudi, melakukan SMS ke pengemudi, melakukan panggilan telepon

6. Aplikasi dan Live merupakan Channels and Context terbaik untuk platform TNC

7. Kecenderungan strategi enabling services platform TNC besar yang beroperasi di Indonesia adalah berupa rekomendasi melalui web untuk partner yang prosedural dan melalui aplikasi untuk partner yang aplikatif

8. Kecenderungan strategi emprowing services platform TNC besar yang beroperasi di Indonesia adalah pengadaan showroom dan pengkreditan untuk pengendara, fitur GPS untuk mempermudah pengendara, pelatihan untuk pengendara, dan sistem reward untuk pengendara yang memiliki performa baik

9. Kecenderungan strategi Other Services platform TNC besar yang beroperasi di Indonesia adalah pengadaan reward dan promo. Strategi tersebut merupakan langkah yang baik untuk penetrasi pasar, dan pengadaan E-Money untuk mempermudah customer melakukan pembayaran

10. Setiap platform TNC besar di Indonesia memiliki Core Value yang berbeda-beda. Core Value dari Go-Jek adalah mengembangkan layanan perjalanan, pembelanjaan, dan kurir. Grab dan Uber adalah mengembangkan layanan perjalanan. Sedangkan Ojek Syari mengembangkan perjalanan khusus perempuan.

11. Komponen dalam Infrastructure dan Core Components yang terpenting adalah web untuk penjelasan mengenai layanan dan aplikasi dari platform itu sendiri

\section{SARAN}

Dari peneliatian ini dapat diberikan saran untuk perbaikan penelitian selanjutnya, antara lain:

1. Untuk penelitian selanjutnya, dapat dilakukan dengan cara membuat peneliatian mengenai kepuasan pelanggan dan pengemudi kemudian dibandingkan dengan aspek strategi yang diterapkan

2. Dapat dilakukan evaluasi terkait strategi yang sudah ditetapkan dengan implementasi pada lapangan sehingga bisa mendapatkan insight yang lebih dalam

\section{DAFTAR PUSTAKA}

[1] L. Menjivar and J. Salazar, "World Economic Outlook," 2016.

[2] United Nations Department of Economic, "World Economic Situation and Prospects 2016."

[3] E. Ianchovichina et al., "Growth Trends in the Developing World: Country Forecasts and Determinants," 2005.

[4] S. Panitchpakdi, "WTO, Globalization and New Technology: Changing Patterns of Competition and New Challenges for Sustainable Industrial Development," in China in the WTO, London: Palgrave Macmillan UK, 2002, pp. 171-178.

[5] J. Poushter and R. Stewart, "Smartphone Ownership and Internet Usage Continues to Climb in Emerging Economies But advanced economies still have higher rates of technology use."

[6] L. Zha, Y. Yin, and H. Yang, "Economic analysis of ride-sourcing markets," Transp. Res. Part C Emerg. Technol., vol. 71, pp. 249-266, 2016.

[7] C. Watanabe, K. Naveed, P. Neittaanmäki, and B. Fox, "Consolidated challenge to social demand for resilient platforms - Lessons from Uber's global expansion," Technol. Soc., vol. 48, pp. 33-53, 2017.

[8] "Transportation Network Companies (TNCs)."

[9] "The user guide," pp. 1-40, 2009.

[10] A. Ca, "Transportation Network Companies Frequently Asked Questions," 2016.

[11] Commissioner Peevey, "Decision Adopting Rules and Regulations to Protect Public Safety While Allowing new Entrants to the Transportation Industry," 2013.

[12] E. Burnette, "Big changes in store for Android Market," ZDNet, 2010. 